\section{A percepção pública da informação sobre os potenciais riscos dos transgênicos na cadeia alimentar}

\section{The public perception of information about the potential risks of genetically modified crops in the food chain}

FURNIVAL, Ariadne Chloë; PINHEIRO, Sônia Maria. A percepção pública da informação sobre os potenciais riscos dos transgênicos na cadeia alimentar. História, Ciências, Saúde - Manguinhos, Rio de Janeiro, v.15, n.2, p.277-291, abr.-jun. 2008.

Resumo

No atual contexto da introdução dos transgênicos na cadeia alimentar brasileira, apresentamos os resultados de estudo que empregou o método qualitativo de grupos focais para levantar as interpretações do público em relação à informação disponível sobre essa inovação biotecnológica. A utilização desse método permitiu gerar resultados que revelaram as relações construídas pelos participantes da pesquisa entre essa modalidade da biotecnologia, as mudanças no meio ambiente e a produção de alimentos em geral. Os resultados apontam particularmente para o modo como os participantes identificaram a falta de informação compreensível, tanto na mídia de massa quanto nos rótulos de produtos, como principal fonte dos seus sentimentos de desconfiança em relação aos transgênicos.

Palavras-chave: percepção de risco; transgênicos; grupos focais;; informação sobre risco; Brasil.

\title{
Abstract
}

At a time when genetically modified (GM) crops are entering the Brazilian food chain, we present the findings of a study that makes use of a qualitative technique involving focal groups to look into the public's interpretation of the information available about this biotechnological innovation. This methodology produced results that revealed the interconnections drawn by the research subjects between this form of biotechnology, changes to the environment, and food production in general. The mistrust expressed about GM crops was particularly attributed by the participants to the non-availability of comprehensible information in the mass media or on product labels.

Keywords: risk perception; genetically modified; crops; focal groups; labeling; information about risk. 
$\mathrm{A}$ s controvérsias surgidas no final do século XX em torno dos organismos geneticamente modificados (OGMs) - os chamados transgênicos - podem ser entendidas como significativo divisor de águas que inaugurou o despertar de interesse maior da sociedade em relação aos processos de inovação tecnológica na área de biotecnologia. Em certos casos, a credibilidade pública de algumas empresas multinacionais atuantes na área foi colocada em questão: por exemplo, frente à resistência do mercado europeu a seus cereais transgênicos, a Monsanto foi obrigada a implementar mudanças radicais nas estratégias de negócios (Barboza, 31 May 2003; Monsanto fails..., s.d.). Testemunhamos resistência semelhante por parte do público em geral no Brasil: Massarani (2000) relata que em 2000 o Jornal do Brasil (11 jul. 2000, primeira página) realizou enquete perguntando "Você é a favor da liberação de alimentos transgênicos?" e obteve os seguintes resultados: contra, 69\%; a favor, 23\%; não se definiram, $8 \%$. Em 2003, o Ibope publicou resultados de sua pesquisa de opinião pública sobre o assunto mostrando que, dos dois mil brasileiros entrevistados, apenas 37\% já tinham ouvido falar dos OGMs; $71 \%$ destes disseram que, se pudessem escolher, prefeririam consumir alimentos que não os contivessem (Ibope, 2003). Essas estatísticas são indicadoras de que, embora ainda haja pouco conhecimento sobre os OGMs no Brasil, manifesta-se a vontade de ser informado sobre a presença desses componentes nos alimentos antes de sua compra. No entanto, é questionável a competência das técnicas de enquete com perguntas fechadas, na captação das referências ambivalentes e complexas do público em geral, para pensar sobre e reagir a assuntos como esse.

Identificamos escassez de pesquisas qualitativas no Brasil na área que trata da compreensão do público a respeito das informações sobre novas tecnologias, como os OGMs, um dos fatores, aliás, que nos incentivaram a realizar nosso estudo numa cidade do interior do estado de São Paulo. A pesquisa focou as percepções de alguns grupos dessa cidade com relação ao contexto da introdução dos transgênicos na cadeia alimentar no Brasil. Nossos objetivos específicos foram: identificar como o público se sente em relação aos OGMs e examinar o que pensa das informações divulgadas na mídia sobre o assunto, explorando suas interpretações pessoais, expressas em conversas do dia-a-dia. A pesquisa resultou em levantamento de dados via a realização de oito grupos focais (GFs), visando revelar em que sentido a compreensão da informação divulgada sobre os OGMs suscita sua aceitação ou rejeição.

Como em outros países (Massarani, 2000), ainda está em curso a polêmica em torno da incorporação dos transgênicos à cadeia alimentar no Brasil. Como nota Oliveira (2004, p.15), "os debates sobre transgênicos ganham contornos altamente polarizados, inviabilizando a possibilidade de se alcançar um consenso sobre as eventuais vantagens da adoção desta tecnologia para os cidadãos". A controvérsia tem-se agravado ainda mais com a mudança de posição por parte do governo brasileiro (Marinho, MinayoGomez, 2004), que, apesar de apoiar retoricamente o Princípio da Precaução ${ }^{1}$, liberou, a partir de março de 2005, a comercialização da soja transgênica no Brasil, cujos efeitos sobre a saúde humana e o meio ambiente, entretanto, ainda não estavam plenamente mensurados e reconhecidos pela comunidade científica (Lewgoy, 2000). Assim, o comportamento do atual governo consolida o plano iniciado no anterior, em vez de adotar postura de precaução. ${ }^{2}$ 
O plantio de soja transgênica no Brasil, liberado desde 2003, coloca o produto na cadeia alimentar. Assim, uma questão central diz respeito ao direito de o consumidor ter acesso a essa informação no rótulo do alimento que consome, o que, entretanto, fez com que o debate público em torno da liberação dos OGMs nos alimentos se restringisse à rotulagem ou não dos produtos e de que forma seria implementada, de modo que possibilitasse a rastreabilidade dos componentes do produto. Isso representa a principal senão a única - frente de 'envolvimento' do público nessa polêmica na sociedade brasileira. Partes desse debate ou de sua falta serão retomadas adiante, na apresentação dos resultados de nosso estudo. Antes, porém, delineamos, nas seções que seguem aspectos da nossa pesquisa, começando com a metodologia.

\section{O método}

Enquadrando-se na grande categoria de pesquisa qualitativa exploratória, o método dos grupos focais (GFs) é indicado para conhecer a realidade cotidiana tal como explicada pelas pessoas que a vivem, permitindo aos pesquisadores e participantes explorar juntos o contexto relacional e imbricado (embeddedness) de seus valores e atitudes (Burgess, Limb, Harrison, 1988a, 1988b). A realização de GFs visa fomentar a interação em grupo com o mínimo possível de envolvimento do pesquisador, que assume o papel de moderador do GF. É essa interação que gera os dados de pesquisa, como notam Barbour e Kitzinger (1999, p. 4; tradução livre): "Em vez de fazer perguntas a cada participante individualmente, os pesquisadores que usam os GFs encorajam os participantes a falar/conversar entre si, fazendo perguntas, trocando informações, comentando as experiências de cada um. No mínimo, os participantes criam uma audiência comum."

A comparação com enquetes e pesquisas de opinião pública, embasadas em questionários constituídos por perguntas fechadas, é útil para apreciar a relevância da interação entre os participantes no GF. Proponentes desse método observam que as pesquisas usando questionários daquele tipo partem do pressuposto de que 'atitudes' e 'opiniões' - e mesmo os termos usados na formulação das perguntas - configuram atributos objetivos cujos significados básicos são estáveis e aceitos universalmente (Grove-White et al., 1997; Waterton, Wynne, 1999) e como tal são passíveis de 'medição'. No entanto, nos GFs as opiniões e atitudes não são de indivíduos per se, mas sim de indivíduos inseridos em realidades multidimensionais, constituídas por redes socioculturais e comunitárias de amigos, colegas, profissionais, parentes, e portanto suas atitudes e opiniões relacionam-se com esses aspectos culturais (Potter, Wetherell, 1987; Wynne, 1991a, 1991b; Wynne, 1995; Yearley, 1999).

Existem diversas recomendações na literatura quanto ao número ideal de grupos num dado estudo: a quantidade de GFs pode variar em relação ao escopo da pesquisa e aos recursos, mas sugere-se realizar minimamente de três a quatro GFs, sendo improvável que novos insights possam surgir com mais de sete ou oito grupos (Morgan, 1997; Krueger, 1994). Quanto ao número de participantes em cada GF, a literatura indica que pode variar de três a 12 pessoas (Barbour, Kitzinger, 1999; Morgan, 1997). Krueger (1994, p.78) nota que "o tamanho ideal para um GF é de seis a nove participantes". Enfatiza-se, contudo, que o importante é a interação fomentada no GF e não necessariamente o número de participantes. 
Os oito GFs realizados em nossa pesquisa foram constituídos do seguinte modo:

1 GF Terceira Idade - misto; cinco participantes da Universidade da Terceira Idade do município.

2 GF Crochê - feminino; sete participantes; realizado num posto de saúde municipal, composto pelas alunas de crochê do local.

3 GF Patrulheiros ${ }^{3}$ - misto; sete participantes; realizado em sala de aula de uma das universidades públicas da cidade.

4 GF Engenharia Física - masculino; cinco participantes; realizado na biblioteca da mesma universidade pública, com estudantes do curso de bacharelado em engenharia física.

5 GF Restaurante Universitário - misto; oito participantes; realizado no pátio do restaurante universitário com os funcionários de uma cooperativa de limpeza.

6 GF Globo Aves - masculino; cinco participantes; realizado com trabalhadores dessa empresa de avicultura, no Sindicato dos Trabalhadores Rurais.

7 GF Coleta Seletiva - misto; seis participantes; realizado no galpão municipal de coleta seletiva, com os catadores da Cooperativa de Coleta Seletiva.

8 GF Escola Técnica - misto; seis participantes; realizado no Sindicato dos Trabalhadores Rurais, com os estudantes da Escola Técnica de Agropecuária.

Com exceção do primeiro e do último GFs, o nível de formação dos participantes era, no máximo, segundo grau completo.

Essa pesquisa seguiu algumas diretrizes daquela realizada no Reino Unido sobre a compreensão pública dos transgênicos, descrita no relatório "Uncertain world" (Grove-White et al., 1997). Nosso roteiro, planejado para que cada GF durasse no máximo hora e meia, procurou levantar desde as opiniões dos participantes sobre os alimentos em geral nos últimos dez anos, até seus conhecimentos e opiniões específicos sobre os transgênicos. Para estimular a conversa, foi usado um quadro de conceitos (concept board) contendo fotos, desenhos e charges retiradas da mídia nacional da época, bem como mostrada uma lista de produtos, já à venda nos supermercados brasileiros, que alegadamente contêm componentes transgênicos. ${ }^{4}$ As discussões foram gravadas ${ }^{5}$, e a massa de dados textuais gerada na forma das transcrições constituiu o material básico para a análise.

\section{A análise dos dados}

Ressaltamos que nossa posição epistemológica é construtivista, ou seja, baseia-se na idéia de que o conhecimento humano é socialmente construído. Os construtivistas não postulam a existência de realidade única, mas sim de múltiplas realidades construídas por seres humanos, que podem ser compartilhadas por grupos inseridos em certos contextos culturais. A compreensão brota da experiência que, por seu turno, é profundamente influenciada pela interpretação que os indivíduos fazem dos eventos. Isso se aplica, evidentemente, tanto aos participantes da pesquisa quanto ao pesquisador. O conhecimento, portanto, surge - é criado - a partir de trocas pessoais entre seres humanos ou entre seres humanos e objetos, em vez de ser descoberto, como se estivesse 'lá fora', objetivamente, 
'esperando' (Guba, Lincoln, 1989; Lincoln, 1990; Woolgar, 1996). Acreditamos, assim, que foram os dados gerados pelos participantes dos GFs que 'nos levaram' aos temas aprofundados neste estudo.

Resultados e discussão

A análise aqui apresentada, embora adequada ao espaço de um artigo, é representativa do relatório final dessa etapa da pesquisa. Do material dos oito GFs aqui considerados, recortamos as seguintes categorias analíticas para discussão:

- os alimentos e o meio ambiente;

- a percepção de riscos nos transgênicos;

- informações sobre os OGMs.

\section{Os alimentos e o meio ambiente}

Embora não se explicitasse como um dos objetivos da pesquisa levantar percepções relacionadas ao meio ambiente, o assunto fez-se notavelmente presente quando se tratava das mudanças nos alimentos nos últimos anos. Constatamos que a maioria dos participantes ressaltou aspectos negativos dos alimentos modernos, principalmente no que diz respeito a percebido uso exagerado de agrotóxicos e outros aditivos químicos, como ilustra este depoimento: "Há dez anos, os alimentos não eram assim cheio daqueles conservantes que colocam nos alimentos. Isso aí é uma coisa que eu acho que não faz bem para a saúde. Não sei não. Não tenho muita opinião para dar, mas sei que mudou barbaridade" (Grupo Crochê).

Notamos também que muitos participantes relacionaram os alimentos naturais com o passado, evocando memórias e imagens, de certa forma bucólicas, de suas infâncias a respeito de hortas verdes e, posto que sem agrotóxicos, saudáveis, e declarando o sentimento de insatisfação por não ter mais tempo nem espaço para fazê-las hoje, como aponta o texto abaixo, representativo de muitos outros: "Ah, eu acho que a [alimentação] de antes era mais natural: tinha mais sabor, não tinha essas coisas que eles misturam hoje em dia para dar mais validade nos alimentos... antigamente era bem melhor" (Grupo Restaurante Universitário).

Percebemos que, embora muitos dos participantes tivessem experiência direta nos ramos agropecuários, não mitificando o caráter árduo desse tipo de trabalho, quando mencionavam hortas caseiras faziam-no com nostalgia, evocando natureza mais conhecida e próxima, mais compreendida e saudável. Os vários relatos de experiência de trabalho nos ramos aviário e agropecuário modernos e industrializados foram permeados por sentimentos de desgosto quanto aos alimentos industrializados, devido ao uso intenso de agrotóxicos (habitualmente referidos como veneno):

CS9 - Eu já trabalhei na lavoura, eu sei. De algodão, amendoim: tudo é passado com veneno. CS8 - Tomate, o veneno usado no tomate é um absurdo...

CS7 - Até o milho, sabe? Até hoje eles ainda passam veneno no milho, por causa da broca, essas coisas.

CS1 - Quando eu era criança, as coisas davam sem passar veneno. É que agora eu não sei o que aconteceu, parece que as terras enfraqueceram muito, precisam de muito adubo e veneno.

CS6 - O tomate também, quando passava veneno, tinha que ficar uma semana sem entrar, para poder colher o tomate, porque o veneno era muito forte. (Grupo Coleta Seletiva) 


\section{A percepção dos transgênicos}

Ao ter solicitadas suas opiniões sobre as mudanças nos alimentos em geral, a maioria dos GFs (seis dos oito) espontaneamente levantou o assunto transgênicos. Cabe lembrar que entre a realização dos primeiros cinco GFs e os últimos três houve na mídia intensa divulgação de notícias referentes ao tema, fomentando mais familiaridade, no mínimo, com a justaposição dos termos transgênicos e alimentos. Mesmo assim, os participantes observaram não haver, na mídia, explicação clara do que seja os transgênicos.

Eles estão vindo com aqueles alimentos... híbricos, não é? Está tendo os alimentos que eles estão fazendo para maior produção, que é o transgênico: é isso. Então está tendo maior exploração em relação às sementes hoje, às mudas... (Grupo Escola Técnica de Agropecuária)

P 6 - Aquela comida, como que chama? Como que chama aquela comida...?

P1 - Genética..., algo assim....

P6 - Que está tendo agora, que estão falando muito no jornal, não sabem se vai poder ou não... Que é de pegar uma fruta e dar outro sabor para ela; é esse negócio de genética, mas eu não sei como é... Como é o nome? Esqueci... Ninguém aqui sabe? (Grupo Patrulheiros)

À exceção de alguns poucos participantes bem informados, houve, em todos os GFs, muitas manifestações de incerteza, dúvida e desconhecimento em relação aos transgênicos nos alimentos. Às vezes tais dúvidas e lacunas de conhecimento traduziram-se em colocações que apontaram para sentimentos de desconfiança quanto a essa biotecnologia, sobretudo quando se expunham suas preocupações em relação aos possíveis efeitos dos transgênicos sobre a saúde humana e o meio ambiente. Vários participantes questionaram o que poderia vir a acontecer às gerações futuras.

P6 - E será que uma pessoa que come alimentos... se for liberado, uma criança que nasce hoje, comendo só alimento transgênico até o final da vida... será que ela vai viver mais do que uma pessoa que come só alimento natural? Eu acho que a pessoa que come só alimento natural vai ter bem mais saúde, vai viver mais...

P1 - Eu acho que com os alimentos transgênicos, a gente só acaba perdendo, né? Para nosso corpo. Acho que quem ganha é só quem acaba fazendo, que daí não gasta com agrotóxicos, e tal; gasta bem menos que você não fazer nada, não tem problema com pragas, e tal, e quem só perde é nós, que acaba pagando o mesmo preço e acaba fazendo mal para nosso corpo, nosso estômago.

P4 -Eu acho que pode até provocar mais problemas da saúde, não é? Como não foi testado. Vai ser testado na hora que fizer mal para a pessoa... (Grupo Patrulheiros)

C1 - Transgênicos eles mudam, fazem a mutação...

C7 -É, porque eu vi comentando outro dia no jornal, sobre esse negócio de plantar soja transgênica; estava afetando os pássaros, porque a abelha, ela vai buscar o néctar da flor, então por causa daquele negócio transgênico lá, acaba afetando até os animais.

C1 - O medo é que acontece alguma coisa e acaba a gente ficando nessa também... mudada em alguma coisa. (Grupo Coleta Seletiva)

Apreciamos aqui a importância da dimensão temporal que os participantes atribuem às mudanças na cadeia alimentar. Como os pesquisadores britânicos ressaltaram nos resultados da pesquisa na qual nos baseamos, os participantes enfatizaram insistentemente a imprevisibilidade dos efeitos de longo prazo e inter-relacionados com outros elementos 
do meio ambiente, decorrentes do uso dessa biotecnologia, em contraste com aqueles riscos já avaliados e, portanto, parcialmente conhecidos e divulgados pela ciência (GroveWhite et al., 1997; ESCRC/GECP, 1999). No GF Crochê, a percepção dos riscos que os transgênicos nos alimentos representam, especialmente na soja, tornou-se preocupação ainda mais reforçada para algumas participantes devido ao fato de os médicos brasileiros hoje recomendarem de modo bastante amplo o uso da soja na dieta alimentar, como alternativa supostamente mais saudável para substituir o tratamento alopático de reposição hormonal. Para essas participantes resta agora a dúvida quanto à possibilidade de essa alternativa não ser de fato tão confiável quanto pensavam:

C5 - Minha irmã está comendo muita soja agora...

C2-É, a mulherada que tem a menopausa; ensinaram para a minha patroa que é bom para menopausa, que é o remédio... (Grupo Crochê)

Os participantes dos GFs inseriram a polêmica dos transgênicos no contexto mais amplo do uso desenfreado de agroquímicos nos alimentos em geral. Como já dito, chamavam comumente os agrotóxicos de 'veneno' e, no momento em que relembravam seu passado, demonstravam insatisfação com os alimentos atuais.

Foi interessante notar que a polêmica em torno dos transgênicos divulgada na mídia, desencadeada principalmente nas esferas econômica e política, despertou a atenção dos participantes com relação à falta de debate mais aberto com a sociedade civil sobre as incertezas quanto à saúde humana e ao meio ambiente. Essa lacuna de diálogo com o público, somada à discussão veiculada na mídia, fomenta desconfiança nessa modalidade de biotecnologia:

\footnotetext{
Se fosse uma coisa garantida, se fosse para o bem da população... Mas não pode ser: apesar de a gente não saber muito sobre isso, a gente tira pela base: se tem bastante gente contra, bastante gente a favor, é porque tem alguma coisa errada no meio, entendeu? Se fosse todo mundo a favor, logicamente que a coisa seria boa, mas se tem contra e a favor é porque tem coisa errada no meio... (Grupo Coleta Seletiva)
}

O senso comum do tipo "onde há fumaça, há fogo", demonstrado nesse depoimento, foi notado por Nelkin (1975) em seus estudos pioneiros sobre disputas técnicas na área ambiental nos EUA, indicando que a mera existência de polêmica e controvérsia em torno das tecnologias emergentes colocou o público em estado de alerta. Desvendou-se até a corrente não-científica e ideológica que permeia o debate, embora muitas vezes ele tenha sido direcionado para visão e discurso altamente tecnocientíficos. Wynne (1995) observa a importância de atentar para o fato de que tais polêmicas e controvérsias esclarecerão as limitações das análises 'objetivas' já aceitas, ressaltando as possibilidades negligenciadas na confusão gerada pela polêmica.

Em alguns GFs notamos que, ao expressarem sua insegurança decorrente da falta de debate aberto e amplo na sociedade sobre os possíveis riscos dos alimentos transgênicos, vários participantes acabaram por contar piadas ou inventar neologismos divertidos, relacionados ao assunto. Assim, entendemos que a lacuna deixada pela falta de debate transparente na esfera pública representa terreno propício para que o imaginário popular associe essa nova tecnologia a problemas, riscos e até ficção científica. Foram evocadas imagens pessimistas e mesmo jocosas da verdadeira 'caixa de Pandora' que está sendo 
aberta pela ciência. As piadas constituem aqui uma forma de 'moldar' e 'amolecer' conceitos alheios, a fim de os tornar mais aceitáveis:

C1 - Se nós soubéssemos que íamos experimentar os transgênicos e ficava boa de cuca, por exemplo, estava bom, não é? O pior é dar uma doença na gente e...

C7 - Agora, você vai começar a comer transgênicos, vai começar a nascer uns galhos em você. [risos]

C7 - Nossa! Você já pensou numa alface saindo a galope aí?! Vai passar correndo, aí você fala "Chega! dessa vez, vou mudar de marca". [risos]

C1 - Isso aí, você sabe o que me faz lembrar? Esses filmes de terror, aquelas plantas gigantes comendo os outros, me faz lembrar isso... [risos] (Grupo Coleta Seletiva)

EF1 - Eu guardo na memória, eu vi uma vez um coelho com gene de tabaco; agora por que você via isso? [risos]

EF4 - Os cara fumava o coelho?

EF1 - Não sei, eu vi uma vez, eu guardei porque achei muito bizarro. Agora, para que servia eu não sei... me chamou a atenção.

EF5 - É, não é todo dia que você vê um coelho com gene de tabaco. [risos]

$\mathrm{EF} 3$ - É, seria legal colocar gene de vaga-lume no milho. Ia ficar brilhando à noite. [risos]

EF2 - Ou então dá uma epidemia, morrem duzentas mil pessoas... aí eu acho que o governo vai se importar; mas eu acho que não vai acontecer isso... Os caras não vão colocar no mercado uma coisa tão venenosa assim, isso é uma coisa que mata aos poucos...

EF4 - Definitivamente não é bom para a empresa, diminui os compradores... [risos] Grupo Engenharia Física)

Referidas justamente nos momentos em que a insegurança em relação aos transgênicos vinha à tona na discussão, as piadas constituíram forma de atenuar suas ansiedades geradas pelos aspectos ainda desconhecidos do assunto (Grove-White et al.,1997).

\section{Informações sobre os OGMs}

Em todos os GFs foi expressa em vários momentos, pelos participantes, a necessidade de mais conhecimento sobre o que consomem, via informações e notícias nos jornais, de modo que lhes permitissem exercer de fato seu direito de escolha como cidadãos e consumidores: “Ah, a gente quer saber, não é? ... Porque a gente nem sabe se está usando isso aí, para falar se é bom ou é ruim. Agora eu não sei se eu já estou usando essa coisa dos alimentos transgênicos. E quero saber!" (Grupo Restaurante Universitário).

Ficou evidente que, para a maioria dos participantes, as principais fontes de informação sobre esse assunto são a comunidade científica e a mídia. Nas falas dos participantes que levantaram questões sobre o papel da comunidade científica, foi explicitada a urgência da realização de mais pesquisas sobre os OGMs nos alimentos. Sempre manifestavam o desejo de que tais pesquisas pudessem contribuir para amenizar suas preocupações sobre os potenciais riscos à saúde decorrentes dessa tecnologia:

TI2 - Os cientistas que sabem têm que nos dizer...

TI1 - Precisa evitar a comercialização desse produto. Não tem as cabeças pensantes? Pega todo esse pessoal químico e vá fazer um estudo real sobre a coisa, mas com o comércio fora do negócio...

TI2 - Da inteligência: precisamos mais informação deles! (Grupo Terceira Idade) 
Em um dos GFs, alguns participantes ponderaram sobre a possibilidade de haver conflito entre os interesses do avanço da pesquisa científica nessa área e o bem-estar social maior:

P3 - Eu acho que não seria legal, esses transgênicos aí, para a gente, não. Mas assim, para a evolução da ciência, para os cientistas, seria legal, mais pesquisas, mais conhecimento. Mas para nós, não...

P2 - Eu também acho... Os cientistas às vezes não pensam na gente, no povo.

P5 - Como assim? A evolução da ciência sempre tem que nos ajudar. (Grupo Patrulheiros)

Ainda que a comunidade científica tenha sido apontada, pelos participantes, como de alta relevância no cenário dos transgênicos no Brasil, uma vez que potencialmente forneceria informações neutras e factuais, ficou evidente que é sobretudo da mídia televisiva que os participantes recebem informações sobre os OGMs. No entanto não se sentem necessariamente informados, pois a maioria demonstrou insatisfação com o fato de não compreender o que a mídia divulga, mesmo acompanhando as notícias, como demonstram estes depoimentos:

CS5 - Eu acho que antes de pôr as coisas no mercado, eles deviam explicar, não é? Explicar melhor, porque todas as campanhas que eles passam, que eles fazem... tem tanta campanha que não precisa, que eles falam tanto [...] A gente tem que se informar de verdade. Assisto tudo isso, mas até hoje não entendi direito isso aí; eu acho que eles deviam ter explicado melhor. (Grupo Coleta Seletiva)

GFC7 - Então, eu assisto muito o Globo Rural de domingo para tentar ficar mais por dentro do que está acontecendo.

GFC2 - Mas mesmo assim, assistindo, não dá para entender.

GFC1 - É isso que eu queria saber: o que é que eles fazem? Porque fala que é transgênico, porque fala que é uma mutação. É isso que eu escutei, é isso que eu te falei, mas eu queria entender isso também. (Grupo Crochê)

Notamos que, para os participantes, a apropriação da ciência pela mídia é muito fragmentada e mais preocupada em gerar sound bytes do que realmente informar para gerar novos estados de conhecimento. O medo do desconhecido, aliado à sensação de 'mãos atadas' por não poder escolher o que comer, levou a maioria dos participantes a concordar que a solução mais imediata seria a rotulagem dos alimentos contendo os OGMs. Vários participantes ressaltaram a questão do direito de escolha:

Se o produto é bom, consegue ter qualidade, durabilidade, por que não informar que esse produto é modificado, que esse produto sofreu esse processo, essa transformação e não vai causar nada ou se vai causar? Puxa, teria que informar isso aí. Aí, a decisão de consumir teria que ser minha. (Grupo Escola Técnica)

Eu acho que devia especificar: "esse é natural", "esse é transgênico", e a pessoa escolhe se quer consumir ou não. (Grupo Patrulheiros)

EF2 - Eu acho que o consumidor tem o direito de saber.

EF1 - Para a pessoa saber o que ela está consumindo; ela tem o direito de saber.

EF2 - É, direito à informação, isso é óbvio, e a comunidade só pode decidir depois que ela tem o conhecimento.

EF2 - Não, eu acho que quem quer conhecer dá para se informar; já existe a informação em algum lugar, mas onde... [risos] 
EF4 - Não, eu acho assim: o mínimo é o direito de saber o que você está comendo. EF5 - Isso é o essencial. (Grupo Engenharia Física)

Quem tem que informar... é o produtor, digamos assim. Quando lança no mercado um produto, isso aí tem que estar em rótulo, entendeu? Então, tinha que ver no governo isso aí, estabelecer uma regra que qualquer produto que entrar no mercado, ele teria que mostrar sua origem. (Grupo Globo Aves)

Na etapa final de cada GF, quando circulamos alguns quadros, charges, fotos e imagens, incluímos os símbolos triangulares contendo um T, que foram aprovados pelo Ministério da Justiça em 2003 para o cumprimento do decreto 8.460, estabelecendo que alimentos que contenham $1 \%$ ou mais de componentes de OGMs sejam rotulados. Contudo ainda não há, nos supermercados, nenhum produto com a indicação apropriada e determinada pelo governo. Há, sim, alguns produtos rotulados sinalizando a inexistência dos OGMs: "produto livre de transgênicos"; "não contém transgênicos". Com exceção de poucos participantes que manifestaram sua satisfação com o símbolo, a maioria fez comentários desdenhosos ou mesmo jocosos, alguns notando sua semelhança com as placas de trânsito ou os símbolos de veneno. Ainda que muitos participantes tenham reconhecido que a rotulagem seja uma possível resposta imediata à questão dos OGMs nos alimentos disponíveis nos supermercados brasileiros, também levantaram diversos problemas que podem vir no bojo dessa 'solução'. Em suas falas, questionaram se o próprio consumidor rotineiramente lê as informações contidas nos rótulos em geral, não se restringindo à data de validade.

\footnotetext{
No supermercado, se um produto for transgênico, isso tem que vir na embalagem. Mas a gente tem preguiça de ler, não é? Eu mesmo acho que é difícil prestar atenção no supermercado. Que nem a validade: de uns tempos para cá [foi] que eu comecei a prestar atenção na validade dos produtos ... . Agora com esse negócio de transgênico, tem que ficar mais esperto ainda. Quando for no supermercado, você vai ter que olhar as embalagens nas latas de óleo ou outros produtos lá, sabe? (Grupo Crochê)
}

Consensualmente, os GFs apontaram a importância da rotulagem, pois fornece informações que subsidiam a tomada de decisão do consumidor. A questão trata do que é realmente informativo. Dizer apenas que um produto contém transgênicos, sem mais detalhes, não seria suficiente de acordo com alguns participantes:

EF4 - Você mostra para a população isso aqui [aponta o símbolo dos transgênicos, o T amarelo]. O que eles vão achar que é isso aqui?

EF6 - Nem vão ter a mínima idéia... (Grupo Engenharia Física)

Ficou óbvia, para os participantes, a improbabilidade de constarem nos rótulos as informações que realmente ajudariam na tomada de decisão em relação aos potenciais riscos à saúde decorrentes do consumo do produto. Além dessa observação, foi mencionada, em dois GFs, a dificuldade de ler as informações impressas nos rótulos:

GA4 - A gente tem que ter o direito de consumir. A gente vai no mercado, então tem que estar lá todas as informações sobre aquele produto, e tem que ser correto, entendeu? ... Eu não vou comprar um produto para minha família que eu estou lendo lá que aquele produto é prejudicial à saúde, entendeu? Então, a informação no mercado, isso aí é fundamental. Tem que estar exposto esse tipo de informação. 
GA2 - Mas esse tipo de informação muitas vezes também não está, não é? GA4 - Não, não está, ou, se está, é com a letrinha mínima.

GA2 - Eu sou jovem e consigo ler, mas tem muitas pessoas idosas que não conseguem ler. Até mesmo jovem, com as informações que o produto é isso ou aquilo, mas não dá para a pessoa entender. (Grupo Globo Aves)

CS7 - O pessoal hoje está mais esperto, não é? Com a mídia, eles estão sabendo mais se defender; o consumidor está mais sabido. Que nem isso aí: apareceu na televisão, mostrando o supermercado e falando sobre os produtos transgênicos, que é obrigado a trazer na embalagem que é transgênico. Quer dizer, o pessoal que é cismado em ficar doente vai correr lá e vai ficar prestando atenção em tudo que é coisa, não é? Vai ler tudo que é letrinha, mas o problema é que eles põem uma letrinha miudinha, e a gente tem problema de vista, aí que é o problema...

CS1 Não consegue nem enxergar - acaba levando os produtos transgênicos mesmo! (Grupo Coleta Seletiva)

Entendemos que na maioria dos GFs houve a percepção de que a rotulagem pode apenas sinalizar a presença dos OGMs num dado alimento, sem informar mais substantivamente a implicação de tal presença, seja positiva ou negativa.

A nosso ver, a questão da rotulagem desses produtos tornou-se praticamente o lócus exclusivo de contato da população com o 'debate público' da introdução dos OGMs na cadeia alimentar, mas ela vem no fim de um longo processo de discussão que tem acontecido sobretudo nos bastidores. A obrigação de rotular enfrentará resistência por parte dos produtores, como é o caso nos EUA (Retzinger, 2001): há setores da sociedade brasileira alegando que "quem vai pagar [pela rotulagem] é o consumidor final" deixa de lado o fato de que, sem a rotulagem, as perdas do exercício da cidadania serão mais altas. É possível visualizar essa questão de um ponto de vista mais prudente, como apontado por Lajolo e Nutti (2003): "Estabelecer a rotulagem é aplicar o princípio de precaução." Embora o princípio de precaução não tenha sido levantado diretamente em nenhum momento nos GFs, pela moderadora ou pelos participantes, nossa avaliação, com base na interpretação dos dados, é de que as opiniões manifestadas em diversas falas, tanto em relação à necessidade da rotulagem quanto à da realização de mais pesquisas e aquisição de certezas sobre o assunto, vieram de encontro ao cerne do princípio: é melhor estar aproximadamente certo no momento certo do que estar precisamente certo, com comprovada evidência científica, mas quando já é tarde demais (Jordan, O' Riordan, 1995).

\section{Considerações finais}

No livro Transgênicos: bases científicas de sua segurança, que defende os OGMs como sendo "até o presente momento, seguros e potencialmente benéficos para toda [a] humanidade" (Lajolo, Nutti, 2003, p.16), os autores concluem o texto com o seguinte comentário:

A engenharia genética, se bem utilizada, junto com outras técnicas convencionais de melhoramento e manejo, tem enorme potencial para aumentar a atividade agrícola, beneficiar o meio ambiente e melhorar a qualidade dos alimentos. Os OGMs mostraram-se seguros para a saúde humana e animal. Mesmo assim, criou-se considerável polêmica sobre o seu uso, abrangendo aspectos sociais, econômicos, culturais e ambientais, além dos científicos, polêmica 
que só será resolvida com a transparência e o encontro entre todos os setores: governo, indústria, consumidores e cientistas (Lajolo, Nutti, 2003, p. 100).

Entendemos que essa polêmica pode vir a contribuir para maior transparência, porque pode chamar a atenção do público para o fato de que ainda há incertezas a debater, como apontado pelos participantes dos GFs desta pesquisa. Oliveira (2004) enfatiza que são escassas, na mídia brasileira, as ocasiões em que as incertezas científicas sobre uma tecnologia são abertamente delineadas e discutidas. Nossa mídia não é diferente de outras no mundo todo quanto à preferência por reportar certezas e 'fatos duros' da tecnologia (Marris et al., Dec. 2001). É relevante notar que a existência da polêmica não necessariamente implica clara delineação das incertezas nos meios de comunicação: ainda predomina a justaposição de opiniões favoráveis e contrárias, o que pouco ajuda o esclarecimento do leitor/telespectador. Como observa Esteves (1998, citado em Oliveira, 2004, p.57):

\begin{abstract}
Quando num debate televisivo sobre problemas ambientais é dada a palavra aos 'representantes' dos diversos campos sociais - econômico, político, cultural, científico, etc. -, esta atitude equivale, por um lado, ao reconhecimento da competência específica de cada um destes campos, relativamente ao assunto em discussão, mas, por outro lado, na justaposição das diferentes opiniões, há como que uma desacreditação da autoridade própria de cada um dos campos - cada posição apresentada é rebatida pelas outras. No fim do debate, como muitas vezes acontece, pouco se terá esclarecido sobre o assunto em discussão, mas da sistemática justaposição das posições divergentes o que sobressai como efeito mais duradouro é o próprio espetáculo do debate, isto é, o jogo midiático da neutralização das posições divergentes, pelo constante 'dar' e 'retirar' a palavra. (grifos do original)
\end{abstract}

Os participantes dos GFs de nossa pesquisa também expressaram que a mídia não tem informado claramente sobre o assunto, mantendo intacto um estado de confusão e fomentando, assim, atitude de simultâneas resignação e desconfiança. Há, então, um paradoxo aqui: a percepção de que a informação explícita disseminada profusamente revela a ignorância e o desconhecimento que rodeiam o assunto do futuro com os transgênicos no mundo.

Como já notamos, o desencadeamento da polêmica alerta o público de que há algo ainda a ser questionado e discutido. Enfim, a existência da polêmica revela que a ciência não é monolítica, nem sua autoridade unânime, incontestável e neutra, mas sim que as controvérsias surgem porque existe desacordo entre os próprios cientistas, como no caso dos transgênicos. ${ }^{7}$ É nesse sentido que a polêmica aponta a necessidade de incorporação da dimensão ética e social dos processos decisórios referentes à liberação e disseminação da biotecnologia alimentar.

O assunto não é apenas científico. É uma questão ética que requer discernimento para evitar danos talvez irreparáveis. A ciência e a tecnologia devem estar orientadas para o desenvolvimento da pessoa humana e para o bem comum e requerem harmonizar-se com os princípios morais. O problema dos transgênicos está em pauta não só na pesquisa dos cientistas, mas pelas vantagens econômicas que podem precipitar, por causa de lucros comerciais, uma série de efeitos negativos (Almeida, 2003, citado em Oliveira, 2004, p.7 ).

Embora a controvérsia surgida na sociedade brasileira sobre os transgênicos tenha revelado que existem discrepâncias de opinião entre os cientistas, permanece entre os participantes dos GFs desta pesquisa a identificação da comunidade científica como a principal fonte de informação potencialmente confiável sobre o assunto, tendo, portanto, 
a 'responsabilidade social' de esclarecer o público a respeito da tecnologia dos OGMs. Na Europa, pesquisas qualitativas encomendadas por alguns governos sobre a recepção pública dos transgênicos mostraram que o público percebe que a 'linguagem corporal institucional' da comunidade científica subvaloriza, e às vezes até nega, as incertezas e os riscos em torno das novas tecnologias, comprometendo a confiança pública na ciência (Grove-White et al., 1997; Grove-White, Macnaghten, Wynne, 2000; ESRC, GECP, 1999). Lembramos aqui que muitos participantes dos GFs de nossa pesquisa justamente expressaram preocupações com relação às incertezas da tecnologia no longo prazo, tendendo a manifestar a opção por ações mais cautelosas. São essas incertezas de longo prazo que dificilmente são captadas em modelos de avaliação de risco e nos sistemas regulatórios baseados em critérios estritamente tecnocientíficos. Ao mencionar os resultados de uma pesquisa realizada com consumidores na Europa, Scott (2001, p. 133) observa:

o público é adiantado em relação a muitos cientistas e policymakers no seu sentimento instintivo para a necessidade de agir de modo cauteloso ... . Atualmente, o público, de forma bem razoável, não confia no uso de uma ciência estreita como uma muleta para justificar a tomada de decisão política em áreas controversas de novas tecnologias. Sabemos agora que a incerteza e ignorância sobre os efeitos das novas tecnologias tais como os alimentos geneticamente modificados são a regra.

Temos como resultado de nossa pesquisa a insatisfação do consumidor com o fato de não ser informado quanto à presença dos OGMs nos alimentos que consome e de não poder dimensionar os efeitos do uso dessa biotecnologia para a saúde humana e do meio ambiente. Ainda que os participantes tenham reconhecido ser a rotulagem uma possível resposta imediata à questão dos OGMs nos alimentos, eles mesmos apresentaram diversos problemas que podem vir no bojo dessa 'solução', já que mais informação não necessariamente significa mais conhecimento. Seria preciso um programa maior envolvendo educação do consumidor, cobrança e fiscalização dos responsáveis, e envolvimento de todos os setores da sociedade com o assunto. Em suas falas, questionaram mesmo se o próprio consumidor rotineiramente lê os rótulos e se os que lêem compreendem seu conteúdo.

Entendemos então que a questão de rotulagem tornou-se o lócus para resolver as multifacetadas dimensões de um debate que deveria estar acontecendo em fóruns públicos, com a participação da sociedade civil, dos cientistas, das ONGs e do governo, pois diz respeito a assunto de interesse geral, referente a sistema que todos atinge, a saber, a cadeia alimentar. A sensibilidade da questão reside justamente nesse fato, pois o consumo necessário de alguns tipos de alimentos pode mesmo, possivelmente hoje, implicar o consumo involuntário dos OGMs. Podemos dizer então, com base nos resultados da pesquisa aqui relatada, que a rotulagem é apenas um esboço, e não a solução definitiva.

Não foi pretensão deste estudo apresentar resultados generalizáveis à população brasileira, mas sim contribuir com uma discussão que reforça a necessidade do alargamento da esfera pública no que se refere aos processos decisórios sobre a liberação e disseminação da biotecnologia alimentar na sociedade. Afinal, são os consumidores brasileiros que "decidem o que entra e o que sai das prateleiras dos supermercados" (Idec, 2004); pelo menos assim deveria ser. 


\section{AGRADECIMENTO}

Agradecemos à Fundação de Amparo à Pesquisa do Estado de São Paulo (Fapesp), que concedeu bolsa de iniciação científica à segunda autora para realizar esta pesquisa.

\section{NOTAS}

${ }^{1}$ Presente no artigo 15 da Declaração do Rio, o princípio de precaução exige que os danos causados ao meio ambiente (natural e social) devem ser evitados de antemão, o que implica a detecção prévia de perigos à saúde e ao meio ambiente via pesquisa científica compreensiva; implica também ação quando ainda não estiverem disponíveis evidência e compreensão científica, ou seja, quando houver suspeita de irreversibilidade, deveria haver ação antes da compreensão científica plena (Boehmer-Christiansen, 1994).

${ }^{2}$ Sobre a trajetória política dos transgênicos no cenário brasileiro, ver Menasche (2000), Nodari, Guerra (2003), Oliveira (2004) e Guivant (2005)

${ }^{3}$ Patrulheiro: jovem na faixa de 14 a 18 anos, que trabalha como estagiário administrativo nas universidades da cidade em que foi realizada a pesquisa.

${ }^{4}$ O Greenpeace elaborou lista de produtos que alega conterem OGMs. Disponível em: http:// www.greenpeace.org.br/tour2004_ogm/guia_consumidor.php.

${ }^{5}$ Usamos equipamento que consegue captar bem as vozes de um grupo de pessoas.

${ }^{6}$ Palavras do professor João Martinez, da Escola Superior de Agricultura Luiz de Queiroz, da Universidade de São Paulo (Esalq/USP), no Seminário Internacional Transgênicos no Brasil, realizado naquela universidade em outubro de 2003.

${ }^{7}$ A exemplo do pedido de desligamento feito por Lia Giraldo, médica e pesquisadora da Fiocruz, em maio de 2007, da Comissão Técnica Nacional de Biossegurança (CTNBio). A cientista queixou-se principalmente da forma como as decisões políticas de governo foram transformadas em 'decisões técnicas' na CTNBio, descaracterizando assim as atribuições oficiais dessa Comissão.

\section{REFERÊNCIAS}

BARBOUR, Rosaline; KITZINGER, Jenny (Ed.). Developing focus group research: politics, theory and practice. London: Sage. 1999.

BARBOZA, David.

Monsanto struggles even as it dominates. New York Times. Disponível em: http://www.biotechinfo.net/monsanto_struggles.html. Acesso em: dez. 2006. 31 May 2003.

BOEHMER-CHRISTIANSEN, Sonja. The precautionary principle in Germany enabling Government. In: O'Iordan, T; Cameron, J. (Ed.). Interpreting the precautionary principle. London: Earthscan, p.31-68. 1994.

BURGESS, Jacquelin; LIMB, Melanie;

HARRISON, Carolyn M.

Exploring environmental values through the medium of small groups: 1 . Theory and practice. Environment and Planning A, v.20, n. 3, p.309-326. 1988a.

BURGESS, Jacquelin; LIMB, Melanie;

HARRISON, Carolyn M.

Exploring environmental values through the medium of small groups: 2 . Illustrations of a group at work. Environment and Planning A, v.20, n.4, p.257-276. 1988b.

ESRC; GECP.

Economic and Social Research Council; Global Environmental Change Programme. The politics of GM food: risk, science and public trust. Brighton and Hove: University of Sussex. Disponível em: http://www.sussex.ac.uk/spru/ documents/gecp_the_politics_of_gm_food_ briefing.pdf. Acesso em: dez. 2006. 1999.

ESTEVES, João Pissarra.

A ética da comunicação e os media modernos: legitimidade e poder nas sociedades complexas. Lisboa:Fundação Calouste Gulbenkian. 1998.

GROVE-WHITE, Robin et al.

Uncertain world: genetically modified organisms, food and public attitudes in Britain. Lancaster: Lancaster University. 1997.

GROVE-WHITE, Robin.; MACNAGHTEN, Phil.; WYNNE, Brian.

Wising up: the public and new technologies. Lancaster: Lancaster University. 2000.

GUBA, Egon; LINCOLN, Yvonna. Fourth generation evaluation. London: Sage. 1989. GUIVANT, Júlia Silvia.

A governança dos riscos e os desafios para a redefinição da arena pública no Brasil. In: CGEE. Ciência, tecnologia e sociedade: novos modelos de governança. Brasília: CGEE, p.47-86. 2005.

IBOPE.

Instituto Brasileiro de Opinião Pública e Estatística. Pesquisa de opinião pública sobre transgênicos. Brasil: Ibope. Disponível em: 
www.idec.org.br/files/pesquisa_transgenicos. pdf. Acesso em: 20 maio 2004. 2003.

IDEC.

Instituto da Defesa do Consumidor. Informações disponíveis em: www.idec.org.br. Acesso em: 15 out. 2004.

JORDAN, Andrew; O'RIORDAN, Tim. The precautionary principle in UK environmental law and policy. In: Gray, Tim (Ed.). UK environmental policy in the 1990s. Basingstoke: Macmillan, p.57-84. 1995.

KRUEGER, Richard.

Focus groups: a practical guide for applied research. Thousand Oaks: Sage. 1994.

LAJOLO, Franco Maria; NUTTI, Marília Regini. Transgênicos: as bases científicas da sua segurança. São Paulo: Sociedade Brasileira de Alimentação e Nutrição. 2003.

LEWGOY, Flávio.

A voz dos cientistas críticos. História, Ciências, Saúde - Manguinhos, Rio de Janeiro, v.7, n.2, p.503-508. 2000.

LINCOLN, Yvonna.

The making of a constructivist: a remembrance of transformations past. In: GUBA, Egon G. (Ed.). The paradigm dialog. London: Sage, p.67-87. 1990.

MARINHO, Carmen L.C; MINAYO-GOMEZ, Carlos.

Decisões conflitivas na liberação dos transgênicos no Brasil. São Paulo em Perspectiva, São Paulo, v.18, n.3, p.96-102. 2004.

MARRIS, C.B. et al.

Public perceptions of agricultural biotechnologies in Europe: final report of the Public Perceptions of Agricultural Biotechnology in Europe research project. Lancaster, UK: University of Lancaster. Disponível em: http://csec.lancs. ac.uk/pabe/docs/pabe_finalreport.doc. Acesso em: 29 abr. 2008. Dec. 2001

MASSARANI, Luisa.

A opinião pública sobre os transgênicos. História, Ciências, Saúde - Manguinhos, Rio de Janeiro, v.7, n.2. 2000.

MENASCHE, Renata.

Uma cronologia a partir de recortes de jornais. História, Ciências, Saúde - Manguinhos, Rio de Janeiro, v.7, n.2. 2000.

MONSANTO fails...

Monsanto fails to identify risks to investors. ProxyInformation. Disponível em: http:// www.proxyinformation.com/monissue.html. Acesso em: dez. 2006. s.d.

MORGAN, David.

Focus groups as qualitative research. London: Sage. 1997.

NELKIN, Dorothy.

The political impact of technical expertise.
Social Studies of Science, London, v. 5, p.35-54. 1975.

NODARI, Rubens; GUERRA, Miguel Pedro. Plantas transgênicas e seus produtos: impactos, riscos e segurança alimentar (biossegurança de plantas transgênicas). Revista de Nutrição, Campinas, v.16, n.1, p.105-116. 2003.

OLIVEIRA, Cláudio Roberto Cordovil. Transgênicos, mídia impressa e divulgação científica: confilitos entre a incerteza e o fato. Dissertação (Mestrado) - Escola de Comunicação, Universidade Federal de Rio de Janeiro, Rio de Janeiro. 2004.

POTTER, Jonathan.; WETHERELL, Margaret. Discourse and social psychology: beyond attitudes and behaviour. London: Sage. 1987.

RETZINGER, Jean Paul.

Setting the agenda - and setting the table - for genetically modified foods in the press. In: Aepeli, Marie-France; Delicath, John W.; Depoe, Stephen. (Ed.). Proceedings of the $6^{\text {th }}$ Biennial Conference on Communication and the Environment. Cincinnati: University of Cincinnati. 2001.

\section{SCOTT, Alister.}

Technological risk, scientific advice and public 'education': groping for an adequate language in the case of GM foods. Environmental Education Research, v.7, n.2, p.129-139. 2001.

WATERTON, Claire; WYNNE, B.

Can focus groups access community views? In: Barbour, Rosaline S.; Kitzinger, Jenny (Ed.). Developing focus group research: politics, theory and practice. London: Sage, p.127-143. 1999.

WOOLGAR, Stephen.

Psychology, qualitative methods and the ideas of science. In: Richardson, J.T.E. (Ed.).

Handbook of qualitative research methods. Leicester: BPS Books, p.11-24. 1996.

WYNNE, Brian.

Public understanding of science. In: JASANOFF, S.; MARKLE, G.E.; PETERSON, James E.; PINCH, Trevor (eds.). Handbook of Science and technology studies. Thousand Oaks: Sage, p.361388. 1995.

WYNNE, Brian.

Public understanding and the management of science. In: Hague, D. (Ed.). The management of science. London: Macmillan, p.143-169. 1991a.

WYNNE, Brian.

Knowledges in context. Science, Technology and Human Values, v.16, n.1, p.111-121. 1991b.

YEARLEY, Steven.

Computer models and the public's understanding of science: a case-study analysis. Social Studies of Science, London, v. 29, n.6, p.435-453. 1999. 